\title{
Reprogramming factors induce proliferation and inhibit apoptosis of melanoma cells by changing the expression of particular genes
}

\author{
YANG WANG $^{1 *}$, HUA-JUN SUN ${ }^{2 *}$, RONG-GUI LI ${ }^{3}$, XIAO-MEI WANG ${ }^{1}$, ZHI-QIANG CHENG ${ }^{1}$ and NAN LOU ${ }^{4}$ \\ ${ }^{1}$ Department of Pathology, Shenzhen People's Hospital, Second Clinical Medical College of Jinan University, \\ Shenzhen, Guangdong 518020; ${ }^{2}$ Department of Pathology, Sichuan Provincial People's Hospital, School of Medicine, \\ University of Electronic Science and Technology of China, Chengdu, Sichuan 610015; ${ }^{3}$ Key Laboratory of Pathobiology, \\ Ministry of Education, Norman Bethune College of Medicine, Jilin University, Changchun, Jilin 130012; \\ ${ }^{4}$ Department of Orthopaedics and Traumatology, The University of Hong Kong-Shenzhen Hospital, \\ Shenzhen, Guangdong 518053, P.R. China
}

Received April 9, 2018; Accepted November 14, 2018

DOI: $10.3892 / \mathrm{mmr} .2018 .9753$

\begin{abstract}
Uncontrolled proliferation and defective apoptosis are two major factors responsible for maintaining the malignant properties of melanoma cells. Our previous study demonstrated that induced expression of four reprogramming factors remodeled the phenotype of B16-F10 mouse melanoma cells into melanoma stem cells. The present study was conducted to investigate the effect of the four Yamanaka reprogramming factors, namely Oct4, Sox2, Klf4 and c-Myc (OSKM), on the proliferation and apoptosis of melanoma cells, and to identify the responsible molecular signals. The results identified that expression of the four reprogramming factors was highly induced by doxycycline treatment in the stable melanoma cell clone that was transfected with a plasmid expressing these factors, driven by the Tet-On element. It was further confirmed that induced expression of these factors enhanced the proliferation and suppressed the apoptosis of the melanoma cells. In addition, induced OSKM expression increased cell proliferation, accelerated the progression of the cell cycle, and
\end{abstract}

Correspondence to: Dr Zhi-Qiang Cheng, Department of Pathology, Shenzhen People's Hospital, Second Clinical Medical College of Jinan University, 1017 Dongmen Northern Road, Luohu, Shenzhen, Guangdong 518020, P.R. China

E-mail: chengzhiqiang2004@aliyun.com

Dr Nan Lou, Department of Orthopaedics and Traumatology, The University of Hong Kong-Shenzhen Hospital, 1 Haiyuan 1st Road, Futian, Shenzhen, Guangdong 518053, P.R. China

E-mail: loun@hku-szh.org

${ }^{*}$ Contributed equally

Abbreviations: OSKM, Oct4, Sox2, Klf4 and c-Myc; SPF, S-phase fraction; PI, proliferation index; DOX, doxycycline

Key words: melanoma, reprogramming factors, proliferation, apoptosis, gene expression upregulated the mRNA expression levels of Janus kinase 2 (JAK2) and Cyclin-B1. Induced expression of these factors also decreased the apoptosis, as well as upregulated B-cell lymphoma 2 (BCL-2) and downregulated BCL-2-associated X (BAX) mRNA expression levels. Taken together, the results suggested that upregulated JAK2 and Cyclin-B1 may be responsible for the enhanced proliferation of melanoma cells, and that BCL-2 upregulation and BAX downregulation may account for the suppressed apoptosis of these cells.

\section{Introduction}

Malignant melanoma is a highly aggressive disease exhibiting drug-resistant behavior (1). Higher melanoma incidence is reported in children and adolescents, whose longer life expectancy than adult patients may be seriously affected (2). Melanoma treatments include conventional surgery, chemotherapy, radiotherapy and biotherapy; however, these are not always successful. Furthermore, certain of these treatment strategies are associated with adverse reactions and/or emergence of drug resistance $(3,4)$, due to the involvement of relatively complicated cellular and molecular mechanisms.

Uncontrolled proliferation and defective apoptosis have been recognized as major factors responsible for the transformation of normal melanocytes into malignant melanoma cells (5). This has been further proven by studies reporting that benign nevi can be transformed into melanoma cells through uncontrolled proliferation and decreased apoptosis $(6,7)$.

The Yamanaka transcription factors: Oct4, Sox2, Klf4, and c-Myc (OSKM) have been successfully used to induce the differentiation of osteosarcoma and breast cancer cells into osteosarcoma stem cells and breast cancer stem cells, respectively (8-11). Our previous study demonstrated that the plasmid expressing these four factors driven by the Tet-On element is transfected into melanoma F10-B16 cells and doxycycline (DOX) is used to induce the expression of these factors in stable transfected cell clones; thus the expression of four reprogramming factors OSKM were induced, remodeling the phenotype of B16-F10 mouse melanoma cells into melanoma stem cells (12). Therefore, the present study was conducted to seek evidence for 
the effect of induced expression of these four reprogramming factors on the proliferation and apoptosis of melanoma cells, as well as to identify the responsible molecular signals involved.

\section{Materials and methods}

Materials. High-glucose Dulbecco's modified Eagle's medium (H-DMEM), sucrose-based solution, SYBR Green PCR Master Mix, Lipofectamine ${ }^{\circledR} 2000$ and Zeocin were obtained from Thermo Fisher Scientific, Inc. (Waltham, MA, USA). Fetal bovine serum (FBS) was purchased from GE Healthcare Life Science (Hyclone; Logan, UT, USA). Doxycycline (DOX) was from Sigma-Aldrich (Merck KGaA, Darmstadt, Germany). The Cell Counting kit-8 (CCK-8) assay kit was provided by Dojindo Molecular Technologies, Inc. (Tokyo, Japan). The Cell Cycle Detection kit was from Beyotime Institute of Biotechnology (Jiangsu, China). The Annexin V/PI Apoptosis Detection kit was purchased from BD Biosciences (San Jose, CA, USA). The RNAiso Plus reagent, polymerase chain reaction $(\mathrm{PCR})$ primers and reverse transcription $(\mathrm{RT})$ reaction kit were purchased from Takara Biotechnology Co., Ltd. (Dalian, China). The plasmids TetO-FUW-OSKM and FUW-M2rtTA were kindly provided by Professor Rudolf Jaenisch (Whitehead Institute for Biomedical Research, Cambridge, MA, USA; Addgene plasmid nos. 20321 and 20342, respectively).

Cell culture and transfection. B16-F10 mouse melanoma cells were obtained from the American Type Culture Collection (Manassas, VA, USA). These cells were maintained in $\mathrm{H}$-DMEM supplemented with $10 \% \mathrm{FBS}$ at $37^{\circ} \mathrm{C}$ in a humidified atmosphere with $5 \% \mathrm{CO}_{2}$. Cell transfection with the plasmid TetO-FUW-OSKM or FUW-M2rtTA was performed using the Lipofectamine ${ }^{\circledR} 2000$ reagent, according to the manufacturer's protocol. After $24 \mathrm{~h}$, the transfection was terminated by washing away the media, following which fresh complete medium was added to the cells. On day 3 , we seeded the cells in a $10-\mathrm{cm}$ plate, and then Zeocin $(400 \mu \mathrm{g} / \mathrm{ml})$ was added at day 5 to start the selection. The cells were checked daily, and the medium was changed when necessary in order to remove dead cells. When the clones were clearly visible and isolated from one another, they were selected, transferred to 96-well plates (one clone/well) and then expanded.

Cell proliferation assay. The transfected cells were seeded into 96-well plates at a density of 1,000 cells/well and incubated at $37^{\circ} \mathrm{C}$ overnight to allow for cell attachment. Then, the expression of OSKM was induced via a Tet-On inducer, DOX $(2 \mu \mathrm{g} / \mathrm{ml}$,). After $0,24,48,72$ and $96 \mathrm{~h}$ of incubation with the control group that absence of DOX, the CCK-8 assay kit was used to respectively evaluate the cell proliferation, according to the manufacturer's protocols. Briefly, following incubation, the cells were incubated with CCK-8 solution, and then the absorbance was determined at a wavelength of $450 \mathrm{~nm}$ with a microplate reader. The absorbance values determined the cell number based on a standard curve of cell numbers against the absorbance value, which resulted from a series of samples analyses in which the cell numbers were known.

Cell cycle progression assay. The B16-F10 cells were plated in $6-\mathrm{cm}$ diameter dishes $\left(0.5 \times 10^{6}\right.$ cells/dish $)$ and allowed to grow for 3 days. A Cell Cycle Detection kit was then used to determine the cell cycle status, according to the manufacturer's protocol. Briefly, the cells were washed with cooled PBS, fixed with $70 \%$ alcohol at for $>2 \mathrm{~h}$. Next, cells were treat ed with RNase A (included in kit) and stained with PI solution. Flow cytometry was then conducted at an excitation wavelength of $488 \mathrm{~nm}$ and analyzed. The percentage of S-phase cells was calculated according to the number of cells at each phase, as follows: $\operatorname{SPF}(\%)=\mathrm{S} /(\mathrm{G} 0 / \mathrm{G} 1+\mathrm{S}+\mathrm{G} 2 \mathrm{M})$. In addition, the proliferation index was calculated according to the following formula: $\mathrm{PI}(\%)=(\mathrm{S}+\mathrm{G} 2 \mathrm{M}) /(\mathrm{G} 0 / \mathrm{G} 1+\mathrm{S}+\mathrm{G} 2 \mathrm{M})$.

Cell apoptosis assay. The cells were plated in 6-cm diameter dishes $\left(0.5 \times 10^{6}\right.$ cells/dish $)$ and allowed to grow for 3 days. Flow cytometry with Annexin V-FITC/PI dual staining was conducted to detect the apoptotic cells, according to the protocol suggested by the manufacturer. Briefly, subsequent to staining with Annexin V-FITC and PI, the cells were analyzed with a FACSCalibur flow cytometer (BD Biosciences). The emitted green fluorescence of Annexin V (FL1) and red fluorescence of PI (FL3) were detected at excitation wavelengths of 488 and $546 \mathrm{~nm}$, respectively, and at emission wavelengths of 525 and $647 \mathrm{~nm}$, respectively. The degrees of early and late apoptosis were determined based on the percentages of Annexin $\mathrm{V}^{+} / \mathrm{PI}^{-}$and Annexin $\mathrm{V}^{+} / \mathrm{PI}^{+}$cells, respectively.

RNA purification and RT-quantitative PCR $(q P C R)$. Total RNA purification and RT-qPCR were performed according to the detailed procedure described in a previous study (13). The primer sets used in the PCR amplification are listed in Table I. Following amplification, a melting curve was generated, and data analysis was performed using Dissociation Curve software, version 1.0 (Applied Biosystems; Thermo Fisher Scientific, Inc.). The normalized value was given by the ratio of the target gene mRNA to the reference gene ( $\beta$-actin) mRNA in each sample.

Statistical analysis. Statistical analyses were performed using GraphPad Prism software, version 5.0 (San Diego, CA, USA). Student's t-test was used to analyze the statistical significance of any differences between two groups. $\mathrm{P}<0.05$ was considered to indicare a statistically significant difference.

\section{Results}

Induction of OSKM expression by DOX treatment. In our previous study, B16-F10 mouse melanoma cells were transfected with a plasmid expressing the four Yamanaka transcription factors, known as OSKM, driven by the Tet-On element. The stable cell clones were then used to study the role of induced expression of these factors. The present study further attempted to ensure the induction of OSKM expression by a Tet-On inducer, DOX $(2 \mu \mathrm{g} / \mathrm{ml})$. The mRNA levels of the OSKM factors were analyzed by RT-qPCR in a selected stable cell clone, cultured in the presence or absence of DOX. As shown in Fig. 1, the expression of the four factors at the mRNAs level was significantly induced by the DOX treatment, when compared with that in cells without DOX exposure. The induction of elevated protein levels has been proven in our previous study (12). These results indicated that 
Table I. Primer sets used in reverse transcription-quantitative polymerase chain reaction.

\begin{tabular}{|c|c|c|c|}
\hline Genes & Primer & Sequence & GenBank no. \\
\hline Oct4 & $\begin{array}{l}\text { Forward } \\
\text { Reverse }\end{array}$ & $\begin{array}{l}\text { 5'-CAGCCAGACCACCATCTGTC-3' } \\
\text { 5'-GTCTCCGATTTGCATATCTCCTG-3' }\end{array}$ & NM_013633.3 \\
\hline Sox 2 & $\begin{array}{l}\text { Forward } \\
\text { Reverse }\end{array}$ & $\begin{array}{l}\text { 5'-GCTCGCAGACCTACATGAAC-3' } \\
\text { 5'-GCCTCGGACTTGACCACAG-3' }\end{array}$ & NM_011443.4 \\
\hline Klf4 & $\begin{array}{l}\text { Forward } \\
\text { Reverse }\end{array}$ & $\begin{array}{l}\text { 5'-CTTCAGCTATCCGATCCGGG-3' } \\
\text { 5'-GAGGGGCTCACGTCATTGAT-3' }\end{array}$ & NM_010637.3 \\
\hline c-Myc & $\begin{array}{l}\text { Forward } \\
\text { Reverse }\end{array}$ & $\begin{array}{l}\text { 5'-TCTCCATCCTATGTTGCGGTC-3' } \\
\text { 5'-TCCAAGTAACTCGGTCATCATCT-3' }\end{array}$ & NM_010849.4 \\
\hline JAK2 & $\begin{array}{l}\text { Forward } \\
\text { Reverse }\end{array}$ & $\begin{array}{l}\text { 5'- CTGGCGAGGTGGTCGCTGTG -3 } \\
\text { 5'- GCCGACCCGCACTGTAGCAC -3' }\end{array}$ & NM_146145.2 \\
\hline Cyclin-B1 & $\begin{array}{l}\text { Forward } \\
\text { Reverse }\end{array}$ & 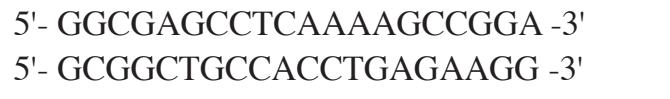 & NM_008655.1 \\
\hline BCL2 & $\begin{array}{l}\text { Forward } \\
\text { Reverse }\end{array}$ & $\begin{array}{l}\text { 5'- ATGGCGCAAGCCGGGAGAAC -3' } \\
\text { 5'- CGCGTCCGCATCTCCAGCAT -3' }\end{array}$ & NM_009741.5 \\
\hline BAX & $\begin{array}{l}\text { Forward } \\
\text { Reverse }\end{array}$ & $\begin{array}{l}\text { 5'- TCCGGGGAGCAGCTTGGGAG -3' } \\
\text { 5'- GGCGGCTGCTCCAAGGTCAG -3' }\end{array}$ & NM_007527.3 \\
\hline CDK1 & $\begin{array}{l}\text { Forward } \\
\text { Reverse }\end{array}$ & $\begin{array}{l}\text { 5'- GTTGCTGGGCTCGGCTCGTT -3' } \\
\text { 5'- GCGGCTTCTTGGTGGCCAGT -3' }\end{array}$ & NM_007658.3 \\
\hline SKP2 & $\begin{array}{l}\text { Forward } \\
\text { Reverse }\end{array}$ & $\begin{array}{l}\text { 5'- TGCCCCAACCTCATCCGCCT -3' } \\
5^{\prime} \text { - ACCGGCTGAGCGAGAGGTGT -3' }\end{array}$ & NM_013787.3 \\
\hline Caspase 3 & $\begin{array}{l}\text { Forward } \\
\text { Reverse }\end{array}$ & $\begin{array}{l}\text { 5'- TCATTCAGGCCTGCCGGGGT -3' } \\
5^{\prime} \text { - TGGATGAACCACGACCCGTCC -3' }\end{array}$ & NM_009810.3 \\
\hline Caspase 9 & $\begin{array}{l}\text { Forward } \\
\text { Reverse }\end{array}$ & $\begin{array}{l}\text { 5'- AGGGTGCGCCTAGTGAGCGA -3' } \\
\text { 5'- CCTGATCCCGCCGAGACCCA -3' }\end{array}$ & NM_015733.5 \\
\hline P53 & $\begin{array}{l}\text { Reverse } \\
\text { Forward }\end{array}$ & $\begin{array}{l}\text { 5'-GGACGATCTGTTGCTGCCCCGAGA -3' } \\
\text { 5'- TGACAGGGGCCATGGAGTGGCT -3' }\end{array}$ & NM_011640.3 \\
\hline$\beta$-actin & $\begin{array}{l}\text { Reverse } \\
\text { Reverse }\end{array}$ & $\begin{array}{l}\text { 5'-CATGTACGTTGCTATCCAGGC-3' } \\
\text { 5'-CTCCTTAATGTCACGCACGAT-3' }\end{array}$ & NM_001101 \\
\hline
\end{tabular}

JAK2, Janus kinase 2; CDK1, cyclin-dependent kinase 1; SKP2, S-phase kinase-associated protein 2; BCL-2, B-cell lymphoma 2; BAX, BCL-2-associated X; Caspase, cysteinyl aspartate specific proteinase.

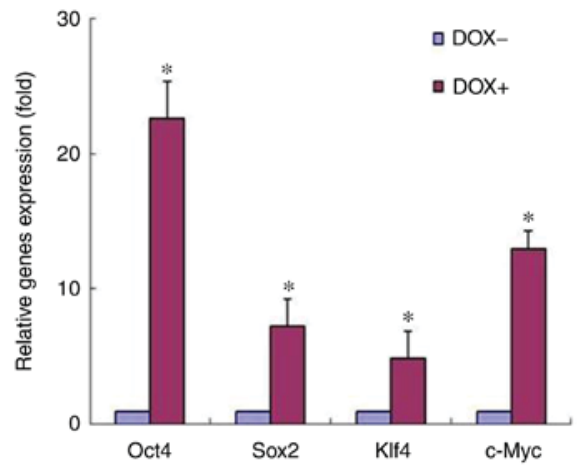

Figure 1. Induction of OSKM expression by DOX treatment. B16-F10 mouse melanoma cells, stably-transfected with TetO-FUW-OSKM, were cultured in the presence or absence of DOX. The OSKM mRNA levels were analyzed using reverse transcription-quantitative polymerase chain reaction and normalized to $\beta$-actin mRNA. The relative fold activation was obtained based on the ratio of the normalized values of the DOX-induced cells to that of the cells without DOX exposure. ${ }^{*} \mathrm{P}<0.01$ vs. cells without exposure to DOX. OSKM, Oct4, Sox2, Klf4 and c-Myc; DOX, doxycycline. high expression of these factors was obtained by treating the melanoma cells with DOX.

Induced expression of OSKM enhances the proliferation of melanoma cells. Uncontrolled proliferation is a crucial factor that characterizes the malignancy of melanoma cells (6). To examine whether induction of OSKM expression was able to enhance the proliferation of melanoma cells, a CCK- 8 cell proliferation assay was used in cells cultured in the presence or absence of DOX. As shown in Fig. 2, cells in the two culture conditions proliferated in a time-dependent manner; however, the cell proliferation was significantly increased following exposure to DOX as compared with that of cells without DOX exposure. These findings indicated that induction of OSKM expression enhanced the proliferation of melanoma cells.

Induced expression of OSKM accelerates the cell cycle progression. The cell proliferation rate is determined by 
the progression of the cell cycle (14). Based on the earlier finding that the proliferation of melanoma cells is enhanced by the induction of OSKM expression, the present study next analyzed the percentage of melanoma cells at each cell division phase following culture in the absence or presence of DOX. The representative histograms of the flow cytometric assay are shown in Fig. 3A, while statistically analyzed data are presented in Fig. 3B. The percentage of S-phase cells and the proliferation index significantly increased in the cells cultured in the presence of DOX, when compared with those in cells cultured in the absence of DOX. Taken together, these results indicated that the induced expression of OSKM enhanced cell proliferation by accelerating cell cycle progression.

Induced expression of OSKM inhibits the apoptosis of melanoma cells. Defective apoptosis is another major factor deciding the malignancy of melanoma cells $(7,14)$. To determine whether induced OSKM expression was able to decrease the apoptosis of melanoma cells, the proportion of apoptotic cells was analyzed through a flow cytometric assay. The representative histograms of the flow cytometric assay are shown in Fig. 4A, while statistically analyzed results are shown in Fig. 4B. As shown in Fig. 4, the percentage of apoptotic cells significantly decreased following exposure to DOX as compared with that in cells without DOX exposure. These results indicated that induction of OSKM expression suppressed the apoptosis of melanoma cells.

Induced expression of OSKM changes the expression of associated genes. To explore the underlying mechanism by which OSKM factors enhance the proliferation and suppress the apoptosis of melanoma cells, the mRNA levels of certain associated genes were analyzed with RT-qPCR. These genes included Janus kinase 2 (JAK2), Cyclin-B1, cyclin-dependent kinase 1 (CDK1) and S-phase kinase-associated protein 2 (SKP2), whose products serve crucial roles in regulating the cell cycle progression and cell proliferation (15-17). In addition, B-cell lymphoma 2 (BCL-2), BCL-2-associated X (BAX), cysteinyl aspartate specific proteinase 3 (Caspase 3 ), Caspase 9 and P53 (also known as transformation-related protein 53) were detected, whose products are important in controlling cell apoptosis (18-21).

As shown in Table II, among the analyzed genes that are associated with cell proliferation, the mRNA expression levels of JAK2 and Cyclin-B1 were significantly increased when the cells were exposed to DOX, as compared with those in cells not exposed to DOX. By contrast, the mRNA expression levels of CDK1 and SKP2 were unchanged in the DOX-induced cells. Among the analyzed genes associated with cell apoptosis, the mRNA level of BCL-2 was increased, while the mRNA of BAX was decreased, when the cells were exposed to DOX. However, the expression of other genes associated with cell apoptosis was unchanged in the DOX-induced cells. The increased expression of JAK2 and Cyclin-B1 mRNAs supported the observation that induced expression of the four OSKM factors enhanced cell proliferation, suggesting that upregulation of JAK2 and Cyclin-B1 may be responsible for the enhanced proliferation. Furthermore, the upregulated BCL-2 and downregulated BAX mRNAs verified the conclusion that induced expression of the OSKM factors was able to suppress cell apoptosis, suggesting that the altered expression
Table II. Induction of OSKM expression by DOX treatment altered the expression levels of associated genes.

\begin{tabular}{lc} 
Genes & Fold change $(\mathrm{DOX}+$ \\
\hline JAK2 & $7.9 \pm 0.81^{\mathrm{a}}$ \\
Cyclin-B1 & $1.8 \pm 0.10^{\mathrm{b}}$ \\
CDK1 & $0.90 \pm 0.07$ \\
SKP2 & $1.22 \pm 0.05$ \\
BCL-2 & $2.4 \pm 0.18^{\mathrm{b}}$ \\
BAX & $0.56 \pm 0.02^{\mathrm{a}}$ \\
Caspase 3 & $1.4 \pm 0.10$ \\
Caspase 9 & $1.3 \pm 0.08$ \\
P53 & $1.39 \pm 0.17$
\end{tabular}

${ }^{\mathrm{a}} \mathrm{P}<0.01$ and ${ }^{\mathrm{b}} \mathrm{P}<0.05$, vs. group without DOX exposure. mRNA levels were analyzed by reverse transcription-quantitative polymerase chain reaction and normalized to $\beta$-actin mRNA. Relative fold activation was calculated based on the ratio of the normalized values of the cells induced by DOX to that of the cells without DOX exposure. DOX, doxycycline; JAK2, Janus kinase 2; CDK1, cyclin-dependent kinase 1; SKP2, S-phase kinase-associated protein 2; BCL-2, B-cell lymphoma 2; BAX, BCL-2-associated X; Caspase, cysteinyl aspartate specific proteinase.

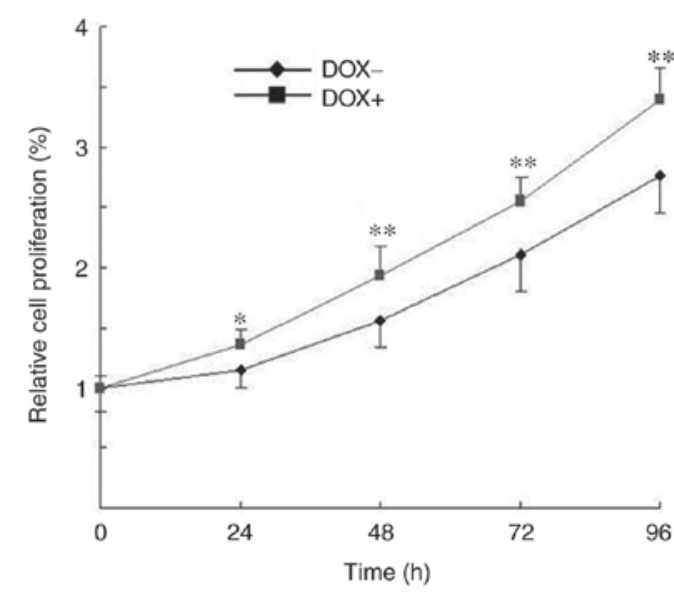

Figure 2. Induced expression of OSKM promoted the proliferation of melanoma cells, as examined using the Cell Counting kit- 8 assay. Relative cell proliferation was calculated based on the ratio of the number of cells at a specific time point over the total number of cells at $0 \mathrm{~h}$. ${ }^{*} \mathrm{P}<0.05$ and ${ }^{* *} \mathrm{P}<0.01$, vs. cells without exposure to DOX. OSKM, Oct4, Sox2, Klf4 and c-Myc; DOX, doxycycline.

levels of BCL-2 and BAX may be involved in the suppression of apoptosis.

\section{Discussion}

The effects of induced expression of the four reprogramming factors on the proliferation and apoptosis of melanoma cells, which are the two major factors affecting the malignancy of the cells, has not been extensively investigated (22). In our previous study, stable B16-F10 mouse melanoma cell clones that were transfected with a plasmid expressing the Yamanaka reprogramming factors, namely OSKM, driven by the Tet-On element, had been used to study the role of the induced 

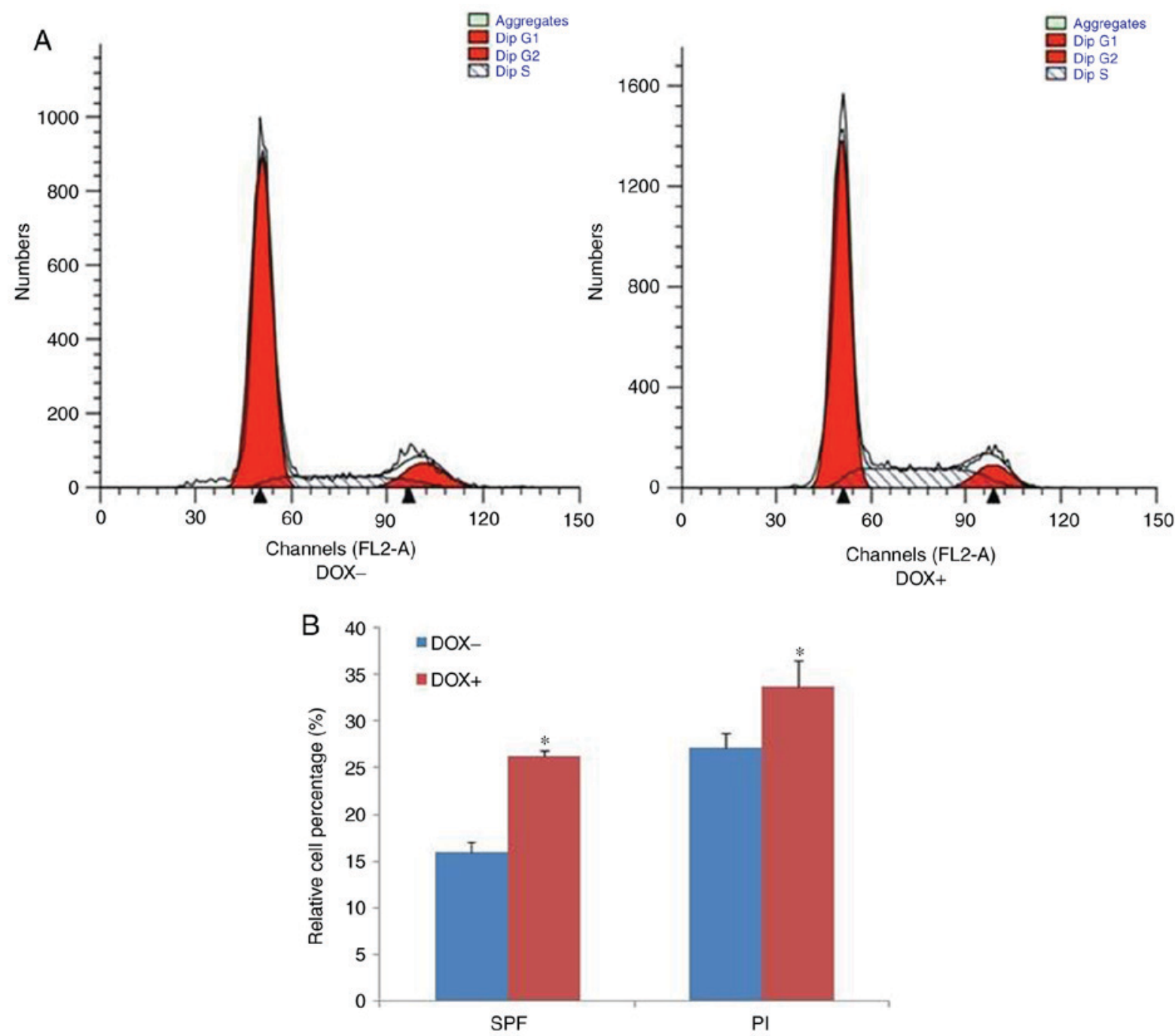

Figure 3. Induced expression of OSKM accelerated the procession of the cell cycle. (A) Representative histograms of the flow cytometric assay, and (B) quantified results of the relative cell percentage are shown. ${ }^{*} \mathrm{P}<0.05$ vs. cells without exposure to DOX. OSKM, Oct4, Sox2, Klf4 and c-Myc; SPF, S-phase fraction; PI, proliferation index; DOX, doxycycline.

expression of these factors in remodeling the phenotype of melanoma cells. In the present study, the effects of these factors on the proliferation and apoptosis of melanoma cells, as well as the involved mechanisms, were investigated. Initially, the mRNA expression of these four factors in a stable cell clone cultured in the presence or absence of DOX was analyzed to ensure that the expression of OSKM was successfully induced. As expected, the mRNA levels of the OSKM factors were significantly enhanced when the cells were exposed to DOX, indicating that high expression of these factors was achieved by DOX exposure. This had also been reported in our earlier study (12), in which high induction of the protein levels of these factors had been observed. Furthermore, this was also supported by the knowledge that the plasmid TetO-FUW-OSKM is a single polycistronic vector encoding the four transcription factors, driven by the Tet-On element $(23,24)$. These results provided the preliminary basis for the next phase of the present study.

The malignant growth of tumors is a complex process, involving activation of sustained growth signals and inhibition of cellular death signals (22). In the present study, it was observed that induction of the expression of the four reprogramming OSKM factors in B16-F10 melanoma cells significantly increased the proliferation and suppressed the apoptosis of melanoma cells. These results indicated that the reprogramming factors were able to elevate the malignancy of B16-F10 melanoma cells, based on the crucial role of uncontrolled cell proliferation and defective cell apoptosis in the development of melanoma and the development of the malignant phenotype of other various tumors $(6,25,26)$. This observation was also supported by other studies reporting that induction of the reprogramming factors increased the cell proliferation rate of mature epithelial cells and Kaposi's sarcoma tumorigenesis $(27,28)$.

To explore the molecular mechanism by which the induced expression of the four reprogramming factors affected the proliferation and apoptosis of melanoma cells, the mRNA levels of the associated genes was analyzed. Special attention was paid to the genes whose functions are involved in cell cycle progression, proliferation and apoptosis. The results revealed that among all analyzed mRNAs associated with cell cycle progression and proliferation, only the mRNA expression levels of JAK2 and Cyclin-B1 were significantly increased, while the levels of other associated genes remained unchanged. These results indicated that JAK2 and Cyclin-B1 upregulation may be responsible for the increased proliferation of melanoma cells, which was induced 

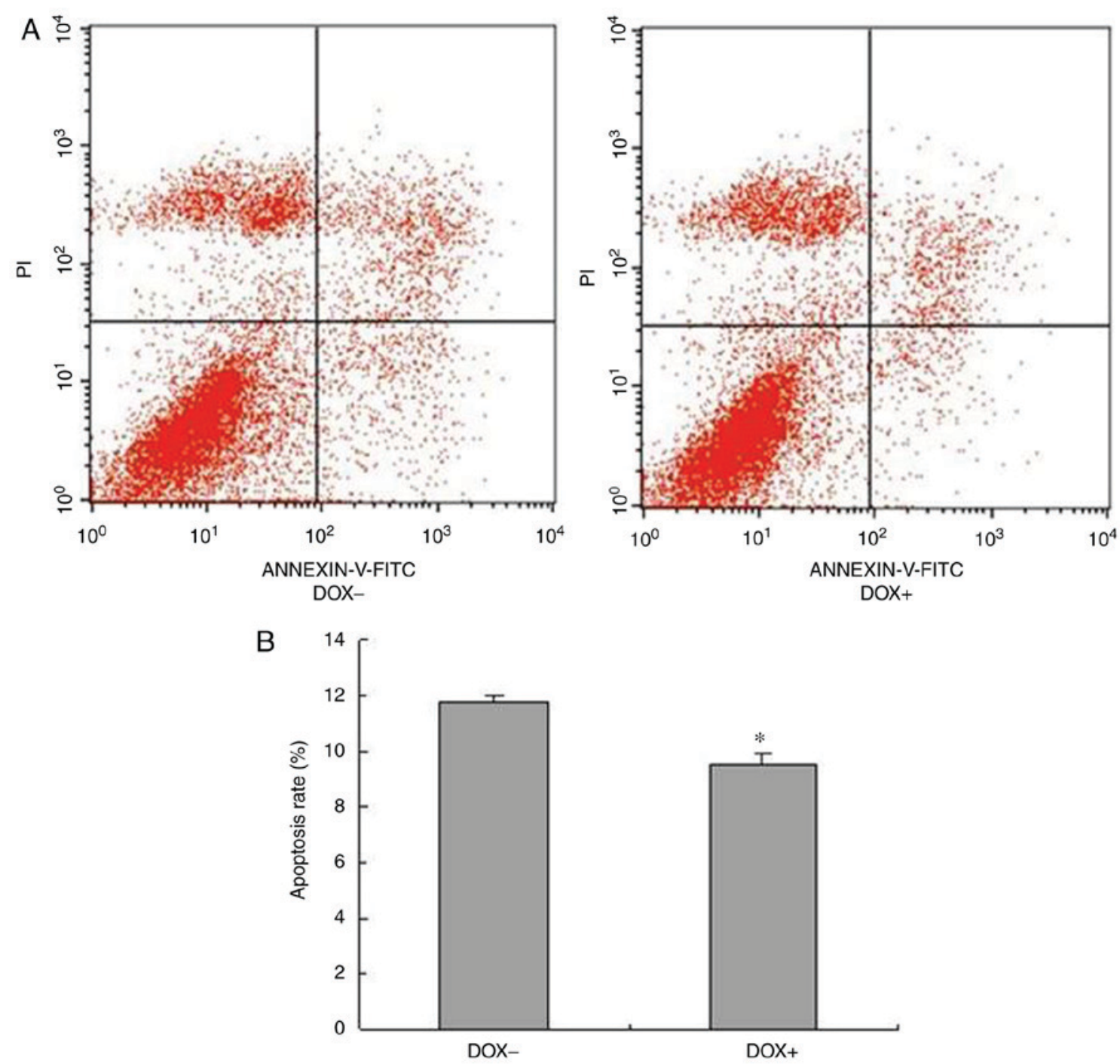

Figure 4. Induced expression of OSKM suppressed the apoptosis of melanoma cells. (A) Representative histograms of the flow cytometric assay, and (B) quantified results of apoptotic cells are shown. Cells at the early apoptosis (Annexin $\left.\mathrm{V}^{+} / \mathrm{PI}\right)$ and late apoptosis $\left(\mathrm{Annexin} \mathrm{V}^{+} / \mathrm{PI}^{+}\right.$) stages were used in the statistical analysis. "P<0.05 vs. cells without exposure to DOX. OSKM, Oct4, Sox2, Klf4 and c-Myc; DOX, doxycycline.

by the reprogramming factors. This finding was supported by other studies reporting that Cyclin-B1 controlled the cell cycle progression and JAK2 upregulated Cyclin-B1 $(29,30)$. Furthermore, the current study demonstrated that among all the analyzed mRNAs that control cell apoptosis, the mRNA expression of BCL-2 was significantly increased and that of BAX was significantly decreased by the induced expression of the reprogramming factors, while all other apoptosis-associated genes were unchanged. These results indicated that the increased expression of BCL-2 and decreased expression of BAX may be responsible for the suppressed apoptosis of melanoma cells, induced by the reprogramming factors. This finding was also supported by previous studies reporting that cell apoptosis was controlled by the upregulation of BCL-2 and downregulation of $\operatorname{BAX}(18,19)$.

In conclusion, the present study observed that induced expression of four reprogramming factors enhanced the proliferation and suppressed the apoptosis of B16-F10 mouse melanoma cells. The enhanced proliferation, indicated by the increase in cell proliferation and accelerated progression of the cell cycle, was found to be associated with upregulation of JAK2 and Cyclin-B1 expression levels. In addition, the suppression of apoptosis was supported by the upregulation of BCL-2 and downregulation of BAX mRNA expression levels. Taken together, the results revealed that upregulated JAK2 and Cyclin-B1 may be responsible for enhanced proliferation, while upregulated BCL-2 and downregulated BAX may be responsible for apoptosis suppression in melanoma cells with DOX-induced OSKM expression.

\section{Acknowledgements}

The authors would like to express their appreciation to Professor F. William Orr from the University of Manitoba (Manitoba, Canada) for his great help in revising the manuscript and to Professor Rudolf Jaenisch from the Whitehead Institute for Biomedical Research (Cambridge, MA, USA) for supplying the plasmids FUW-M2rtTA and TetO-FUW-OCT4 of Addgene.

\section{Funding}

No funding was received. 


\section{Availability of data and materials}

The datasets used and/or analyzed during the current study are available from the corresponding author on reasonable request.

\section{Authors' contributions}

YW provided the related materials and methods from previous studies, and made substantial contributions to the study conception and design. H-JS analyzed and interpreted the data. R-GL and X-MW wwere involved in the data collection and disposal, the manuscript drafting and critical revision. Z-QC and NL conceived and designed parts of the study and agreed to be accountable for all aspects of the work in ensuring that questions related to the accuracy and integrity of any part of the work are appropriately investigated and resolved. All authors read and approved the final manuscript.

\section{Ethics approval and consent to participate}

Not applicable.

\section{Patient consent for publication}

Not applicable.

\section{Competing interests}

The authors declare that they have no competing interests.

\section{References}

1. DeSantis CE, Lin CC, Mariotto AB, Siegel RL, Stein KD, Kramer JL, Alteri R, Robbins AS and Jemal A: Cancer treatment and survivorship statistics, 2014. CA Cancer J Clin 64: 252-271, 2014.

2. Hoang MT and Eichenfield LF: The rising incidence of melanoma in children and adolescents. Dermatol Nurs 12: 188-189, 2000.

3. Dudek-Peric AM, Ferreira GB, Muchowicz A, Wouters J, Prada N, Martin S, Kiviluoto S, Winiarska M, Boon L, Mathieu C, et al: Antitumor immunity triggered by melphalan is potentiated by melanoma cell surface-associated calreticulin. Cancer Res 75: $1603-1614,2015$.

4. Ribas A, Hamid O, Daud A, Hodi FS, Wolchok JD, Kefford R, Joshua AM, Patnaik A, Hwu WJ, Weber JS, et al: ssociation of pembrolizumab with tumor response and survival among patients with advanced melanoma. JAMA 315: 1600-1609, 2016.

5. Bandarchi B, Jabbari CA, Vedadi A and Navab R: Molecular biology of normal melanocytes and melanoma cells. J Clin Pathol 66: 644-648, 2013

6. Croce CM: Oncogenes and cancer. N Engl J Med 358: 502-511, 2008.

7. Zhao H, Tang W, Chen X, Wang S, Wang X, Xu H and Li L: The NAMPT/E2F2/SIRT1 axis promotes proliferation and inhibits p53-dependent apoptosis in human melanoma cells. Biochem Biophys Res Commun 493: 77-84, 2017.

8. Takahashi K and Yamanaka S: Induction of pluripotent stem cells from mouse embryonic and adult fibroblast cultures by defined factors. Cell 126: 663-676, 2006.

9. Levings PP, McGarry SV, Currie TP, Nickerson DM, McClellan S, Ghivizzani SC, Steindler DA and Gibbs CP: Expression of an exogenous human Oct-4 promoter identifies tumor-initiating cells in osteosarcoma. Cancer Res 69: 5648-5655, 2009.

10. Beltran AS, Rivenbark AG, Richardson BT, Yuan X, Quian H, Hunt JP, Zimmerman E, Graves LM and Blancafort P: Generation of tumor-initiating cells by exogenous delivery of OCT4 transcription factor. Breast Cancer Res 13: 94, 2011.
11. Corominas-Faja $\mathrm{B}$, Cufi $\mathrm{S}$, Oliveras-Ferraros $\mathrm{C}$, Cuyàs $\mathrm{E}$, López-Bonet E, Lupu R, Alarcón T, Vellon L, Iglesias JM, Leis $\mathrm{O}$, et al: Nuclear reprogramming of luminal-like breast cancer cells generates Sox2-overexpressing cancer stem-like cellular states harboring transcriptional activation of the mTOR pathway. Cell cycle 12: 3109-31024, 2013.

12. Wang Y, Mou Y, Zhang H, Wang X, Li R, Cheng Z and Liu X: Reprogramming factors remodel melanoma cell phenotype by changing Stat3 expression. Int J Med Sci 14: 1402-1409, 2017.

13. Wang Y, Wei Y, Zhang H, Shi Y, Li Y and Li R: Arsenic trioxide induces apoptosis of p53 null osteosarcoma MG63 cells through the inhibition of catalase. Med Oncol 29: 1328-1334, 2012.

14. Sherr CJ: Principles of tumor suppression. Cell 116: 235-246, 2004.

15. Pan XW, Chen L, Hong Y, Xu DF, Liu X, Li L, Huang Y, Cui LM, Gan SS, Yang QW, et al: EIF3D silencing suppresses renal cell carcinoma tumorigenesis via inducing $\mathrm{G} 2 / \mathrm{M}$ arrest through downregulation of Cyclin B1/CDK1 signaling. Int J Oncol 48: 2580-2590, 2016.

16. Kralovics R, Passamonti F, Buser AS, Teo SS, TiedtR,Passweg JR, Tichelli A, Cazzola M and Skoda RC: A gain-of-function mutation of JAK2 in myeloproliferative disorders. N Engl J Med 352: 1779-1790, 2005.

17. Xu J, Zhou W, Yang F, Chen G, Li H, Zhao Y, Liu P, Li H, Tan M, Xiong $X$ and Sun Y: The beta-TrCP-FBXW2-SKP2 axis regulates lung cancer cell growth with FBXW2 acting as a tumour suppressor. Nat commun 8: 14002, 2017.

18. Ashkenazi A, Fairbrother WJ, Leverson JD and Souers AJ: From basic apoptosis discoveries to advanced selective BCL-2 family inhibitors. Nat Rev Drug Discov 16: 273-284, 2017.

19. Carrington EM, Tarlinton DM, Gray DH, Huntington ND, Zhan Y and Lew AM: The life and death of immune cell types: The role of BCL-2 anti-apoptotic molecules. Immunol Cell Biol 95: 870-877, 2017.

20. Herr I and Debatin KM: Cellular stress response and apoptosis in cancer therapy. Blood 98: 2603-2614, 2001.

21. Ferraz da Costa DC, Fialho E and Silva JL: Cancer chemoprevention by resveratrol: The p53 tumor suppressor protein as a promising molecular target. Molecules 22, 2017.

22. Hainaut P and Plymoth A: Targeting the hallmarks of cancer: Towards a rational approach to next-generation cancer therapy. Curr Opin Oncol 25: 50-51, 2013.

23. Hockemeyer D, Soldner F, Cook EG, Gao Q, Mitalipova M and Jaenisch R: A drug-inducible system for direct reprogramming of human somatic cells to pluripotency. Cell Stem Cell 3: 346-353, 2008.

24. Carey BW, Markoulaki S, Hanna J, Saha K, Gao Q, Mitalipova M and Jaenisch R: Reprogramming of murine and human somatic cells using a single polycistronic vector. Proc Nati Acad Sci USA 106: 157-162, 2009.

25. Imran A, Qamar HY, Ali Q, Naeem H, Riaz M, Amin S, Kanwal N, Ali F, Sabar MF and Nasir IA: Role of molecular biology in cancer treatment: A review article. Iran J Public Health 46: 1475-1485, 2017.

26. Celia-Terrassa $T$ and Kang Y: Distinctive properties of metastasis-initiating cells. Genes Dev 30: 892-908, 2016.

27. Guo L, Karoubi G, Duchesneau P, Shutova MV, Sung HK, Tonge P, Bear C, Rogers I, Nagy A and Waddell TK: Generation of induced progenitor-like cells from mature epithelial cells using interrupted reprogramming. Stem Cell Reports 9: 1780-1795, 2017.

28. Gramolelli S and Ojala PM: Kaposi's sarcoma herpesvirus-induced endothelial cell reprogramming supports viral persistence and contributes to Kaposi's sarcoma tumorigenesis. Curr Opin Virol 26: 156-162, 2017.

29. Qian X, Tan C, Yang B, Wang F, Ge Y, Guan Z and Cai J: Astaxanthin increases radiosensitivity in esophageal squamous cell carcinoma through inducing apoptosis and G2/M arrest. Dis Esophagus 30: 1-7, 2017.

30. Toyoshima-Morimoto F, Taniguchi E, Shinya N, Iwamatsu A and Nishida E: Polo-like kinase 1 phosphorylates cyclin B1 and targets it to the nucleus during prophase. Nature 410: 215-220, 2001.

This work is licensed under a Creative Commons Attribution-NonCommercial-NoDerivatives 4.0 International (CC BY-NC-ND 4.0) License. 